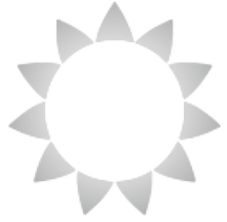 \\ Anthropology \& Aging \\ Journal of the Association for Anthropology \& Gerontology
}

\section{Time and Collective Biology: Relationships between Individual and Societal Life Course Ideologies in Mexican Men's Sexual Health Treatment}

\author{
Emily Wentzell \\ University of Iowa \\ emily-wentzell@uiowa.edu
}

\begin{abstract}
People may seek to embody cultural ideals of the life course through their use or rejection of medical interventions, including but not limited to anti-aging treatments. Here, I analyze this phenomenon via interviews with men engaging with two different forms of sexual health medicine in urban Mexico: erectile-dysfunction treatment and testing for sexually transmitted infections (STIs). I argue that, in contrast to the biomedical understanding of patients as individuals who change during their lives, my interlocutors understood themselves as components in broader "collective biologies" that change on a longer timeline. These are culturally-defined groups that people understand to be comprised of interrelated members whose behaviors concretely affect the group's physical and social well-being over time. In both medical arenas discussed here, men used or rejected sexual health interventions in response to local narratives about the nature of the Mexican population as a collective biology, including ideas about how it should change over time away from its roots in the colonial past. They characterized predispositions to machismo and disinterest in preventative health care as embodied inheritances that the Mexican population should reject in order to achieve healthpromoting modernity in the future. My analysis describes how these interlocutors sought to live out desirably modern forms of race and gender through their medical decisions in a way that they hoped would contribute to positive, embodied change in the Mexican social body over time. These findings show that, despite the assumptions of individualism generally naturalized in anti-aging treatment and biomedicine, people may make medical decisions in an effort to aid collective change over population-level timescales.
\end{abstract}

Keywords: Life course; temporality; masculinity; sexual health; anti-aging medicine; Mexico

Anthropology \& Aging, Vol 42, No 1 (2021), pp. 66-80

ISSN 2374-2267 (online) DOI 10.5195/aa.2021.232

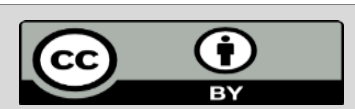

This work is licensed under a Creative Commons Attribution 4.0 International License.

This journal is published by the University Library System of the University of Pittsburgh as part of its

D-Scribe Digital Publishing Program, and is cosponsored by the University of Pittsburgh Press. 


\title{
Time and Collective Biology: Relationships between Individual and Societal Life Course Ideologies in Mexican Men's Sexual Health Treatment
}

\author{
Emily Wentzell \\ University of Iowa \\ emily-wentzell@uiowa.edu
}

\begin{abstract}
Anthropologists have long investigated how people's experiences of time reflect ongoing relationships between individual and group-level experiences. These experiences include people's understandings of the relationships between themselves and their societies in light of shared ideas about groups' origins, pasts, and desired futures (Munn 1992; Tamarkin 2018). Such studies have been particularly useful for understanding how cultural expectations for change over time relate to ideals and experiences of gendered personhood. For example, some scholars have analyzed how body-modification practices help people embody gendered social expectations associated with particular rites of passage or expected forms of change over the life course (cf. Boddy 1989).
\end{abstract}

Since Western biomedicine plays a key role in many people's everyday lives, anthropologists have studied the use of biomedical technologies to assess bodily change over time, and to attempt to align those changes with medical norms and cultural ideals (e.g., Jain 2007; Manderson and Smith-Morris 2010). As other articles in this volume discuss (Kroløkke, this issue; Sievert et al., this issue), this phenomenon is especially apparent in reproductive and sexual health medicine. In that arena, health practitioners and patients use medical interventions in efforts to align bodies with norms of gender and modernity, and by assisting or preventing reproduction, ${ }^{1}$ they aim to pursue individuals,' families,' and societies' hopes for the future. For instance, anthropologist Tine Gammeltoft's (2013) work analyzes the relationship between Vietnamese women's experiences of gestational time as mediated by ultrasonography as well as the future-altering, traumatic, and teratogenic past of war. Studies of such relationships further highlight that expectations for change over time are social constructs that people attempt to naturalize and live out through both medical and social interventions (Johnson-Hanks 2002). This approach also highlights the non-linearity and contingency of people's embodiments of expected life courses, as in anthropologist Caroline Bledsoe's examination of Gambian women's use of hormonal birth control to promote reproductive healing rather than prevention (Bledsoe 2002).

The globalization of biomedical interventions, often encoded with Western cultural norms of gender, personhood, and the life course, creates a situation in which people may experience competing local versus imported norms for change over time in their bodies and behaviors. Disjunctions between these norms are growing more apparent as people worldwide are living longer lives that are increasingly shaped by biomedical interventions. Popular, globalized discourses of 'successful aging' highlight these possible disjunctions. Promoting healthy or successful aging is often framed by health and socialsupport professionals as supporting older people's rights and well-being. However, what counts as "healthy" or "successful" usually means "ideal to contemporary Euro-Americans," i.e., numeric aging coupled with ongoing physical and behavioral youthfulness, activeness, and independence (Lamb 2014, 2017). 
Promoting these culturally-specific ideals as "healthy" has the consequence of pathologizing other ideals of how bodies and behavior should change over time; it also risks stigmatizing people who depart from those norms (Estes and Binney 1989). Moreover, it has fueled, and been fueled by, the development of the "anti-aging" medical industry (Fishman, Binstock, and Lambrix 2008). Anti-aging medicine both naturalizes Western ideals of eternal youth and frames medical practice itself as modern and even futuristic (Mykytyn 2006). This field overlaps significantly with sexual and reproductive health medicine in that it provides ways to perform reproductive and sexual functions-once socially and/or biologically limited to earlier phases of life-for extended periods of time. Medicalizing these aspects of biology has meant defining gender stereotypes as biologically "natural" (Riska 2013). This is exemplified by foci on extending the "biological clock," which reduces women's personhood over time to a race to reproduce before senescence (Friese, Becker, and Nachtigall 2006) and extending men's ability to maintain virile and vigorous masculinity as expressed through unceasing penetrative sexuality (Marshall 2009). ${ }^{2}$ Yet, while many embrace medical technologies as a way to live out ideals for gender, personhood, and the life course, others may find these norms undesirable or inappropriate (cf. Potts et al. 2004).

Furthermore, while anti-aging medicine is a particularly clear-cut case of culturally-specific life-course norms becoming naturalized in medical practice, such norms reverberate even through healthcare spheres seemingly unrelated to age. For example, the area of preventing and testing for sexuallytransmitted infections (STIs) features debates about the appropriate age to vaccinate for human papillomavirus (HPV) as well as critiques of under-screening for STIs in older populations assumed not to be sexually active (despite increasing and conflicting pressure to be 'sexy seniors') (Casper and Carpenter 2009; Marshall 2010, 211; Minichiello et al. 2012). As I discuss below, people's attitudes towards STI testing are also intimately related to their perceived role in societal changes over time, such as the adoption of "modern" self-care and sexual self-determination (Adkins 2001; Biehl, Coutinho, and Outeiro 2001).

In this article, I map some specific points of disjunction between the ideals and assumptions regarding masculinity, the male life course, and male biology encoded in two arenas of Mexican men's sexual health medicine. Specifically, I analyze data from a study of older, working-class men who were experiencing decreased erectile function but rejected treatments for erectile dysfunction (ED) and from a study of heterosexual, middle-class couples participating in medical research on the occurrence of HPV in men.

I discuss how, in both cases, people understood their intimate medical decisions, sex lives, and health behaviors as influenced by - and capable of further influencing-generational change over time in the broader Mexican social body. Participants attributed characteristics like machismo and a lack of interest in preventative health care to a shared biological and cultural Mexican nature rooted in the nation's history. As such, they intended for their own sexual and health behaviors to make embodied contributions to hoped-for change on the population level. I describe how their health decisions drew implicitly on cultural understandings of people's individual bodies and behaviors as innately influenced by a population-level past, and as capable of altering its future. I argue that their individual decisions, explanations of their changing behavior, and hopes for those behaviors' long-term positive effects for others drew upon a shared notion of the Mexican population as what I call a "collective biology." Collective biologies are culturally-defined groups that people understand to be comprised of interrelated members whose behaviors concretely affect the group's nature and well-being on a time scale beyond the individual life course. This concept is meant to serve as an umbrella term for locallyspecific ways in which people understand some individuals' actions to have embodied consequences for a specific group of others. 
In the following, I discuss the specific ideology of collective biology that influenced people's actions in the two ethnographic arenas I studied. I then focus on findings from each setting in order to discuss how this ideology informed people's varied understandings of the ways their embodied sexual and health behaviors reflected a shared, bio-social Mexican past and might contribute to its future. I conclude by discussing how people's hopes that their embodied actions and changes in their individual life courses might contribute to positive generational change on a collective level directly conflicted with the teleologies that have been naturalized in anti-aging and sexual health medicine.

\section{Gender, health, and time in Mexican notions of collective biology}

Popular cultural notions of "Mexicanness" suggest that individual sexual and health behaviors concretely affect the health and well-being of the national populace as a biologically and culturally interrelated whole. It is important to note that anthropologists understand racial categories to be cultural ideas about human difference-which then profoundly influence peoples' lives, opportunities, and health - rather than scientifically valid biological distinctions (Ackermann et al. 2019). Thus, I am discussing context-specific ideologies and not biological facts when I discuss race, Mexicanness, or mestizaje, which is the mix of Conquistador forefathers and indigenous foremothers popularly understood as the origin of a uniquely Mexican population.

The idea that contemporary Mexicans do or should comprise a homogenous, mestizo racial group has been promoted since the Revolution of 1910 for key political reasons, e.g., unifying the population to enable its governance, promoting the enculturation and absorption of indigenous peoples, and justifying the marginalization of groups who do not conform to this homogenization project (Alonso 2004; Manrique 2017). This ideology has been used to promote a specific kind of unity-conformity to the health, gender, and other behaviors associated with contemporary visions of modernity. Intellectuals and politicians have promoted the belief that mixing of people of indigenous and Spanish heritage would eventually lead to an ideal race (e.g., Vasconcelos [1925] 1997). For instance, physicians expected women's pelvises to reach an ideal midpoint between presumptively too-narrow European and too-wide indigenous forms (Cházaro 2005). The notion of the Mexican or mestizo population as a collective biology - with a shared biological and cultural essence-has thereby been naturalized through these discourses.

Such attitudes and interventions have further fostered the idea that individuals can advance this mestizo racial whole, and thus the Mexican nation, by performing modern health and gender behavior. Postrevolutionary public-health campaigns have tasked women with the role of mothers who should reproduce modern ideas of health and hygiene as they planned families and raised children (Soto Laveaga 2007; Stern 1999), and mestizo-identified healthcare workers continue to critique patient behavior and self-presentation that they consider to be anti-modern, unhygienic, or problematically indigenous (Smith-Oka 2012).

Thus, ideas of embodied teleology are central to the ideology of Mexicanness. This ideology positions contemporary Mexicans, who- and whenever they are, as mestizos carrying innate and often negative inheritances from an indigenous and colonial past. They are expected to contribute to biological and behavioral population improvement over time by acting in modern ways. The eugenic and antiindigenous elements of this ideology have become implicit rather than explicit over time; the open discussions about how to create evolution within la raza (the race), which were commonplace in the early half of the 1900s, have since faded away (Manrique 2016; Stepan 1991). Yet, these ideas continue to echo in certain arenas, such as the continuing marginalization of indigenous people in healthcare as discussed above, in national scientific projects built on the assumption of a homogenous, mestizo 
populace (García-Deister and López-Beltrán 2015; Nieves Delgado 2020), and especially in discussions of gender.

Discussions of Mexican machismo exemplify this ideology. The notion of Mexican men as inherently macho-emotionally closed and obsessed with power, invulnerability, and virility-became popular in the 1950s and consequently became identified with what it meant to be a Mexican man. This conceptualization stems from the idea that the Mexican populace is a coherent racial group, formed by the reproductive mixing of Spanish Conquistador forefathers and indigenous foremothers. Innate machismo is seen as men's biological and cultural inheritance from the violent and coercive character of that reproduction (see Paz [1961] 1985).

Like the broader ideology of race from which it stems, this characterization of "natural" masculinity is a cultural concept rather than a biological fact (López-Beltrán and Deister 2013; Moreno Figueroa and Saldívar 2015). Machismo has always been a stereotype obscuring more complex lived realities and gender (as well as racial/ethnic) diversity (Gutmann 1996). Nevertheless, it has been central to Mexican men's understandings of themselves for the past 70 years. This remains true today, although the ways in which people relate to the concept have changed dramatically in the past several decades.

The participants in the studies I discuss below have lived through major changes in cultural ideals of gender and masculinity. This generation of men had been raised with the belief that good men marry, father children, and provide economically for their families - while engaging in frequent extramarital sexual encounters and locating their leisure lives outside the domestic sphere. Many were raised to see machismo as a normative attribute of men who met these societal expectations. However, they have lived through increasingly strong and influential calls to enhance gender equity in the domestic and public spheres, as well as widespread adoption of the idea that such a change would represent a way to live out desirable modernity on the population level (García and de Oliveira 2004). Ideals of love and marriage have also changed with the widespread idealization of "companionate marriage," in which people seek out monogamous relationships intended to provide emotional fulfillment and intimacy, in addition to the more traditional marital goals of economic stability and reproduction (Hirsch 2003; Wardlow and Hirsch 2006). ${ }^{3}$ Current ideals of masculinity combine responsible provision with emotional support for one's family and monogamous, intimate marriage; these are often explicitly framed as anti-macho (Ramirez 2009; Wentzell and Inhorn 2014).

Nevertheless, people in Mexico continue to keep the concept of machismo alive by framing it as a problematic bio-cultural inheritance against which good men must struggle, rather than simply an inaccurate description or outmoded form of masculinity (Amuchástegui Herrera 2008; Amuchástegui and Szasz 2007; Brandes 2002; Ramirez 2009). Critiques of the persistence of machismo and articulations of hope for a more egalitarian future are now central to popular cultural discussions of the ideal life course of the Mexican social body. Below, I discuss how individuals expressed ideas about Mexican collective biology and its past and possible change over time in relationship to their own experiences with sexual health medicine.

\section{Changing erectile function and ideal masculinities in Mexico}

Viagra and other ED medications have been the blockbusters of the overlapping fields of anti-aging and sexual medicine. In the late 1990s, age-related decrease in erectile function and emotion- or relationshiprelated "impotence" were redefined as ED, a problem of individual biology that could be treated pharmaceutically (Tiefer 2006). In the years since, global marketing and prescription of ED drugs have widely distributed the Euro-American cultural assumptions that shaped the inception of ED as a disease 
category. While individual peoples' and health practitioners' ideas about ED and how to treat it vary, the global marketing of and media discussion about ED have been remarkably consistent. Its key features include metaphors of bodies as machines and age-related changes as breakdowns to be fixed; phallocentric and individualistic ideas of male sexuality as an individual trait rather than a relational experience; and understandings of "healthy" aging as necessarily including the unceasing performance of youthful-style sexuality (Grace et al. 2006; Mamo and Fishman 2001; Marshall and Katz 2002; Tiefer 1994). In short, ED drugs have come to serve as "masculinity pills" that enable men to align their bodies with culturally-specific ideals of gender and aging (Loe 2004, 58).

The pharmaceutically-mediated promise of never ending virility despite aging or illness would seem to resonate with stereotypes of Mexican masculinity. ED drugs have been available in Mexico since their emergence on the global scene. They quickly became pop culture mainstays, frequently featuring in television-comedy punchlines. There was even an advertisement on the "Viagra"-printed mints I received after dinner at a seafood restaurant (a joking riff on the idea of seafood as an aphrodisiac, the owner explained). As is clear in the names of herbal copycat treatments such as "Powersex" and "Mforce," understandings of ED drugs as 'masculinity pills' aligned with notions of Mexican men's predisposition to machismo.

\section{Study 1: Men's experiences of decreased erectile function}

I found that men's relationships to the notion of machismo and its critiques-especially the idea of temporality and development over time in a collective Mexican racial group-fundamentally influenced their understandings of changing erectile function as they aged. In 2007-8, I interviewed over 250 male urology patients, most in their 50s and 60s, in a government-run, hospital-based clinic in the central Mexican city of Cuernavaca. I held interviews in Spanish and transcribed then translated the portions quoted here into English. Patients tended to be working-class and older and were usually seeking treatment for urological complaints other than ED. Our open-ended, ethnographic interviews ranged widely but focused on the men's health problems, life histories, changes in sexual functionality, and their experiences of medical treatment. A detailed discussion of the study and methods can be found elsewhere (Wentzell 2013), and this research was approved by the University of Michigan and IMSS Institutional Review Boards.

Almost 70 percent of the men I interviewed reported decreases in erectile function. However, only 11 percent considered medical treatment for this bodily change, and only a few had tried ED drugs. Although ED drugs offered the promise of aligning their bodies with youthful or macho sexuality despite aging and illness, my interlocutors' narratives revealed this to be precisely why they rejected those interventions. Instead, most participants understood age-related changes in sexual function as opportunities to align their bodies and behavior with the emergent, anti-macho ideals of masculinity.

Many study participants saw a decrease in sexual function as a lessening of their innate, biological urges towards infidelity that had aligned them with outmoded machismo rather than currently ideal forms of masculinity. For instance, a retired laundry worker who identified himself as, in his words, a former "womanizer," believed that he had recently become a better husband because, “The truth is, now I don't have the same [erectile] capacity." He continued to explain that a physical inability to cheat had enabled him to begin cultivating mutual respect in his marriage: “I'm 55, I know what I am. I don't want problems with my wife. Like I deserve respect from her, she deserves it from me as well." For men like him, biologically-induced fidelity became an aid for living out contemporary ideals of masculinity and marriage. Some men understood this shift as also reflecting the increased wisdom they associated with 
proper aging. For example, an appliance repairman discussed his newfound fidelity by noting mental as well as physical changes. He said, "With age, you start to think more."

Thus, decreased erectile function and the fidelity these men believed it to facilitate enabled their performance of both desirably modern and age-appropriate masculinities. Participants expected respectable older men to focus on the home and family rather than chasing sex. Discussing the absurdity of old men chasing women, a barber laughed and said, "Here in Mexico, we have a saying: 'After old age, chickenpox.' It means that some things become silly when one is older." My interlocutors further understood the pursuit of youthfully vigorous sexuality in older age not only as socially inappropriate but also as physically harmful. Several said that they expected their bodies to slow down following lifetimes of hard work. Thus, they feared that pharmaceutically 'accelerating' their bodies with ED drugs could cause damage and even death. Reflecting this common idea, one retiree stated that, "Viagra scares me." This is especially notable since participants did not voice similar fears about drugs taken to treat other conditions, such as high blood pressure.

Thus, in contrast to the pathologization of aging encoded in ED drugs, these men overwhelmingly saw a decrease in age-related sexual function as normal. They naturalized the idea discussed above that demanding, and thus appropriately masculine, work lives led to general and sexual slowing in later life. For instance, a delivery-truck driver explained, "My work is a little rough, heavy. I carry a lot, so I feel a little tiredness. Now, I can't have as much sex as before. This is normal. Now it's not the samewhen I was young, more potency. Now with my age, not anymore." The men's wives often promoted this normalization of change when their husbands first began to experience decreased erectile function. One construction worker was initially concerned about this change. However, he said that his wife told him that she would rather spend time together than have sex. He became "dedicated to the home" instead of "wander[ing] the streets," and both his marriage and remaining sex life underwent a "beautiful change." Free of what he characterized as the "sick mind" that had led him into a youth of infidelity, he reported that decreased erectile function had engendered the development of a more companionate marriage.

Overall, many of my interlocutors had little interest in ED drugs because they saw decreasing erectile function as a bodily reprieve from the innately macho tendencies that they considered to be both culturally outmoded and inappropriate for respectable older men. ${ }^{4}$ Many articulated that they expected to begin a "second stage" or "another level" of life that would focus on new priorities like being a "role model" for their grandchildren-a life that did not feature penetrative sex. A retired factory worker summed up this valorization of change with the comment, "Erectile dysfunction isn't important. When I was young, it would have been, but not now." These urology patients understood their male bodies and behaviors to be fundamentally influenced by an innately Mexican impulse to machismo; however, they embraced age-related physical "slowing" as an aid for the adoption of currently valorized masculinities. They felt that bodily aging had freed them from their macho urges, enabling them to behave in ways that are consistent with an emerging societal future. Their discussions of machismo drew implicitly yet powerfully on culturally-specific ideas of collective biology and its past and future change over time. Their explanations rooted their own past behavior in a trait inherited from their imagined Spanish Conquistador forefathers. They further linked men's own later-life cessation of stereotypically macho sexuality to future-oriented calls for "modern" rather than macho masculinities.

\section{Treating collective biologies in men's sexual health research participation}

People participating in a quite different sexual-health arena similarly drew upon implicit ideas of Mexican mestizaje amid changing gender norms in order to make sense of men's medical experiences. 
This was the case for the heterosexual male participants in the Mexican sub-study of the multinational "Human Papillomavirus in Men," or "HIM," study. This longitudinal, observational study aimed to reveal the 'natural history' of HPV in men by testing large groups of men in various sites and then to track their acquisition and clearance of the virus in relation to other health factors, such as smoking. Twice annually for four or more years, HIM study participants underwent genital swabbing to determine the presence of HPV DNA; at the same time, they also provided other samples for STI testing, completed sexual- and health-history questionnaires, and were informed about prior test results. The Mexican HIM study was administered by the Cuernavaca research unit of a federal health organization, and researchers recruited participants mainly from that health system (both workers and patients) as well as from large local businesses with employees who could access the system by virtue of their employment. This created a participant pool that skewed towards middle- and working-class men with relatively high levels of education and job stability compared to the local population.

From 2010-13, I conducted a series of annual interviews with 31 of these male participants together with their wives as well as with comparison groups of 10 male participants and 12 female partners individually. HIM staff recruited these participants from the pool of men who suggested their female partners for inclusion in a planned (but never executed) study of HPV in women. These interviews were intended to capture the ways in which spouses jointly constructed understandings of men's medicalresearch experiences. The interviews were structured according to best practices for talking with couples together. They included open-ended questions that addressed people's relationship and life histories, medical experiences, decision-making and experiences relating to HIM enrollment and HPV test results, as well as change over time from year to year. I discuss study methods in detail elsewhere (Wentzell 2015, 2021); this research was approved by the University of Iowa and IMSS Institutional Review Boards.

\section{Study 2: Participants' experiences of the Human Papillomavirus in Men Study}

In contrast to the men discussed in the previous section, who hoped to embody societal change by behaving differently in later life, HIM study participants of all ages generally saw themselves as consistently embodying modern gender and health behavior through their involvement in medical research. They often conceptualized the potentially embarrassing, intimate testing required by the HIM study as proof that they were not machos, but instead modern men whose efforts to be healthy were not hamstrung by problematically traditional gender ideologies. For instance, a hospital clerical worker said that, while "In our culture it's not a given that the Mexican man understands health, because there's a lot of machismo," he himself was willing to participate because, "I'm Mexican but not macho." Participants thus subscribed to the common notion that machismo was a racially innate trait that modern Mexican men should ideally reject, and they sometimes considered the frequent STI testing that HIM participation required as support for doing so. For instance, another hospital clerical worker explained how his negative HPV test results helped him to remain faithful. He recalled, "I thought, 'Good, I'll keep sticking to one partner.' You see the consequences that having many partners could have. It's better to be safe. All the tests are negative, so it's better that I keep myself that way." Thus, the men's participation in the sexual-health research was temporally marked, serving as an area and an aid for aligning themselves with modern versions of masculinity and male sexuality.

They also used the HIM study to live out their visions of modern, companionate marriage. Wives participating in interviews often characterized their husbands' participation in this medical research as direct care for themselves-in both the biological and social sense. Since they saw spouses' bodies as intimately interlinked, participants expected that the men's HPV test results would reveal the female partners' status as well. For example, a male IMSS facilities worker believed that if he tested negative 
for HPV, "then as a consequence, she'll also be OK, it seems to me, right? That's a really interesting point that helped me become a study subject." In this way, the men's willingness to submit to potentially embarrassing genital sampling served as an act of marital care.

The men's willingness to disclose their test results to their wives was a similarly meaningful expression of intimacy. Since testing positive for an STI was often perceived as a sign of infidelity-and positive STI status is often stigmatizing-sharing results was a clear statement of trust and vulnerability. Couples thus performed companionate marriage by engaging jointly with the HIM study and its results. A male engineer diagnosed with HPV explained that, since "we've taken [the diagnosis] maturely, it really hasn't affected us." He recounted that his wife "was there with me when they gave me the results ... it wasn't hard because we've always kept everything open." They were thus able to frame potentially distressing STI results as an opportunity to live out a form of marriage associated with desired modernity.

Spouses similarly incorporated the men's HIM participation into their efforts to raise modern families and inculcate their children with anti-macho gender ideologies. A nurse who stated that "gender equity is very important" to her family had suggested that her bartender husband join the study when she heard about it at work. He said, "Normally here [in Mexico,] a man finds it very difficult to let [any health professional] touch his intimate parts, and well, I got accustomed to it, now I see it as something normal ... and like that, between jokes, we're transmitting all that to our sons." In this comment, he linked his own experience over time to the ongoing task of raising anti-macho sons, and thus the longerterm, societal-level project of moving towards what many Mexicans view as modern gender and health norms. For some men, transmitting health-promoting gender ideologies went hand-in-hand with the goal of supporting future scientific advances. For instance, a physician said that his participation in the medical research enabled him and his wife to "hope that, for them [future generations,] there will be fewer problems with aggressive diseases." Overall, many participants in the HIM study hoped to support the development of medical advances that would protect future generations, while also transmitting the social predilection to use such advances.

Some participants' hopes relied on specifically collective visions of modernity, the Mexican populace, and the family units that comprise it. A health service worker explained this perspective by saying, "I tell my wife that now I don't just think of myself, but of what I bring with me, which is her and my children." His wife, a homemaker, added, "My father had a saying he would tell us, that when one marries, your life no longer belongs to you, it belongs to your husband or your wife." She added, "When you have children, then again your life isn't yours, it's your children's." This ethos of living for others extends the impact of one's actions - such as the men's HIM participation-beyond the individual body and life course, framing people as components of broader bio-social entities rather than as detached individuals. This ethos also encourages people to understand their own bodily health as a collective resource. For instance, a male hospital facilities worker explained, "If I' $m$ in good health, I know that in a given moment if there's any emergency, I know that I can take care of my people." From this perspective, engaging in modern self-care through STI testing enables participants to care for the health of those intimately related to them in the present moment. It also allows them to model health and gender behaviors that, when taken up by their children and others, will enhance the health and wellbeing of broader collective biologies in the future.

This includes modernizing the Mexican populace from within by performing anti-macho masculinities and health-promoting self-care. HIM participants and their partners tended to see themselves as a middle-class vanguard, educated enough to embrace modern comportment but not elite enough to be tempted into the ruling-class corruption, which they universally saw as moving their country backward. 
From this position, they sought to advance the mestizo collective biology. For instance, many explicitly discussed their goal to promote a "culture of prevention." In a typical statement, a hospital clerical worker mused that the HIM study "is good because we [in Mexico] don't really have the culture of, of prevention, right?" As such, he thought that more people getting tested before they develop health problems could promote such a culture.

Along similar lines, some HIM participants hoped they would serve as models for both their peers and their children. For instance, a retired utility worker explained, "I think that our case can serve as an example for the people around us, because they observe us also." This promotion of preventative care was fundamentally interconnected with the promotion of modern masculinities. As a medical office worker noted, "In our culture, it's not a given that the Mexican man" understands or cares for his health, "because a lot of machismo exists." He hoped to model difference from this "lack of culture." Such hopes incorporate a cultural notion of teleology, as they focus on moving Mexican men away from the problematic past embedded in their biology and toward a future of modern behavior that will also enable better health.

HIM participants and their partners hoped that these health behaviors could protect the future population against a range of ills with both cultural and biological components. Parents frequently looked to the HIM study as a source of health information that they could share with their children as they taught them more broadly about modern and protective behaviors. A business executive critiqued the "traditional" parenting she had received and said that, in contrast, she cultivated emotional intimacy with her children. This included sharing STI-related knowledge gleaned from her interactions with the HIM study. She said, "I talk with them all the time ... [even though] sometimes we start touching on things that embarrass me... They're growing and developing, and they have more contact with sexual issues, drugs, the security problems in our country."

Overall, my interlocutors often framed themselves as agents of change whose behavior could help to heal the ills of their broader collective biologies. They saw actions like participation in the HIM study as a way to enhance the interlinked health of couples and families. Through modeling progressive, antimacho action and contributing to future medical advances, it was also a way to promote health and gender behavior that would enhance the well-being of the Mexican populace as a bio-social whole. This collectivist understanding of men's participation in medical research was revealed through the metaphors participants often used to discuss it. The physician quoted above hoped to be a "positive statistic" in a hypothetical quantitative assessment of Mexican health behavior, while a driver described his participation as a "little grain of sand" that would contribute to all of the other actions by his fellow grains of sand on the metaphorical Mexican beach. Similarly, the bartender quoted earlier hoped his participation in HIM could "start a snowball effect" of healthy masculinity; this metaphor in particular seems to capture people's understanding of themselves as components of collective bio-social wholes that could be pushed forward along the long timeline to modernity by the actions of individuals enmeshed in the Mexican societal aggregate.

\section{Conclusion: Treating individual versus collective bodies and temporalities}

The examples I have described here demonstrate how people may relate bodily changes and biomedical experiences into raced and gendered expectations for change over time that diverge from the norms embedded in Western biomedicine. In Mexico, and in context-specific ways elsewhere, men have articulated that changing their health and sexual practices is a desirable but difficult way to perform modern masculinity and personhood (de Keijzer 2016; de Keijzer and Rodriguez 2007; Escobar Latapí 2003; Sandberg 2011; van der Geest 2001). In my research, decreased erectile function emerged as a 
facilitator of this change. Similarly, STI testing and diagnosis may function as a threat to or as an aid in the performance of idealized masculinities, depending on patients' positionality, gender ideology, and expectations of behavior and embodiment across the life course (cf. Shoveller et al. 2010). For example, many HIM participants used HPV surveillance as an arena for performing gendered modernity, responsibility, and marital care.

Divergences between expectations of natural and healthy male change over time were quite clear in my research on erectile function; here, Mexican men rejected the opportunity to embody 'successful aging' and become 'sexy seniors' with ED drugs. The disjunctures in assumptions about men's fundamental biology were equally important but more subtle in the HIM study in which health researchers sought to understand the "natural history" of HPV. While the medical study was framed longitudinally, it tracked changes over time in individual bodies and in a population conceived of as an aggregate of individuals. In contrast, participants understood their involvement primarily in relation to their aim of fostering change in collective biologies-including their own family and the general Mexican populace-on a generational timeline.

In both cases, the local racial ideology of mestizaje profoundly influenced men's experiences of bodily change and medical intervention. Their understandings were influenced by the idea of mestizo Mexicans as components of a broader racial whole, biologically and culturally interconnected and moving slowly from colonial and indigenous backwardness towards health-enhancing modernity. This notion meant that, in different but related ways, both working-class men experiencing decreased erectile function and middle-class men being tested for HPV understood their own bodily experiences as contributing to the enhancement of a collective mestizo biology over time. Men in the ED study sought to align their bodies with changing societal values, as aging freed them from embodying a collective past, while those in the HIM study sought to embody the healthy future they desired for the Mexican populace.

My analysis suggests that-beyond the problem of Western biomedicine naturalizing reductive understandings of masculinity as unceasing virility-men's sexual-health medicine also encodes assumptions about biology and the life course as fundamentally individual, which may not match the patients' own embodied understandings. A Western emphasis on individuality is present in this medical arena-from understandings of sex as an individual rather than a relational activity (Tiefer 1994) to the public-health understanding of populations as collections of individuals rather than largerthan-individual bio-social entities. This leads to a set of conflicting life course ideologies and norms for aging. Biomedical interventions and research tend to focus on tracking and minimizing individual biological change over time, while people might instead understand that their own bodily experiences reflect and contribute to collective change on a generational rather than an individual time scale. Given this state of affairs, interventions like ED medications which, from one perspective, can appear to promote modern and healthful aging may, from another perspective, seem like impediments to ageappropriate change and a contribution to societal modernization. The examples discussed here highlight the need to attend to collective ideas of biology - and people's own expected life courses or temporalities - in both research on and the practice of sexual and reproductive medicine.

\section{Endnotes}

1. Of course, the confluence of gender, time, and technology goes beyond medical technology as well. While writing this paragraph, I received a \#womencrushwednesday bitmoji from a friend who explained that she had learned about this hashtag on social media; it was apparently a response to \#mencrushmonday. 
2. Virility medicine has its own fascinating teleology, coming in and out of vogue in biomedicine and other healing systems in response to varying cultural and structural changes. It is often used to support wide-ranging conceptions of 'normal' and 'healthy' masculinity and male sexual function (e.g., McLaren 2007; Oudshorn 1994; Watkins 2008; Wentzell 2008; Zhang 2015). The current iteration of this trend took off with the 1998 introduction of the blockbuster ED medication Viagra. It was followed by several other brands as well as pharmaceutical treatments for other bodily experiences or changes over time that had previously been considered 'normal' or simply caused by life experience or emotion. This includes the burgeoning trend of diagnosing men with 'low testosterone' and treating them with hormone supplements as well as the use of selective serotonin reuptake inhibitors (SSRIs) to treat premature ejaculation (Tiefer 2006; Vitry and Mintzes 2012).

3. Research indicates that younger men have also used reproductive health related-changes, like vasectomy, as ways to live out masculine responsibility (Gutmann 2007; Huerta Rojas 2007).

4. Additional factors, like men's economic status and healthcare access, also played key roles in relation to their changing erectile function; see Wentzell 2013.

\section{References}

Ackermann, Rebecca, Sheela Athreya, Deborah Bolnick, Agustín Fuentes, Tina Lasisi, Sang-Hee Lee, Shay-Akil McLean, and Robin Nelson. 2019. "AAPA Statement on Race and Racism." American Association of Physical Anthropologists. http://www.physanth.org/about/positionstatements/aapa-statement-race-and-racism-2019/

Adkins, Lisa. 2001. "Risk Culture, Self-Reflexivity and the Making of Sexual Hierarchies." Body \& Society 7 (1): 35-55.

Alonso, Ana María. 2004. “Conforming Disconformity: 'Mestizaje,' Hybridity, and the Aesthetics of Mexican Nationalism." Cultural Anthropology 19 (4): 459-490. doi: https://doi.org/10.1525/can.2004.19.4.459.

Amuchástegui, Ana, and Ivonne Szasz, eds. 2007. Sucede que me Canso de ser Hombre. Mexico City: El Colegio de Mexico.

Amuchástegui Herrera, Ana. 2008. "La masculinidad como culpa esencial: subjetivación, género y tecnología de sí en un programa de reeducación para hombres violentos." II Congreso Nacional Los Estudios de Género de los Hombres en México: Caminos Andados y Nuevos Retos en Investigación y Acción, Mexico City, February 14.

Biehl, João, Denise Coutinho, and AnaLuzia Outeiro. 2001. "Technology and Affect: HIV/AIDS Testing in Brazil." Culture, Medicine and Psychiatry 25 (1): 87-129.

Bledsoe, Caroline H. 2002. Contingent Lives: Fertility, Time, and Aging in West Africa. Chicago: University of Chicago Press.

Boddy, Janice. 1989. Wombs and Alien Spirits. Madison, WI: University of Wisconsin Press.

Brandes, Stanley. 2002. Staying Sober in Mexico City. Austin: The University of Texas Press.

Casper, Monica J., and Laura M. Carpenter. 2009. "Sex, Drugs, and Politics: the HPV Vaccine for Cervical Cancer." In Pharmaceuticals and Society: Critical Discourses and Debates. Edited by Simon J. Williams, Jonathan Gabe, and Peter Davis, 71-84. Malden, MA: Wiley-Blackwell.

Cházaro, Laura. 2005. “Mexican Women's Pelves and Obstetrical Procedures: Interventions with Forceps in Late 19th Century Medicine." Feminist Review 79: 100-115. 
de Keijzer, Benno. 2016. "Sé que debo parar, pero no sé cómo'”: Abordajes teóricos en torno a los hombres, la salud y el cambio." Sexualidad, Salud y Sociedad: Revista Latinoamericana (22): 278300 .

de Keijzer, Benno, and Gabriela Rodriguez. 2007. “Hombres Rurales: Nueva generación en un mundo cambiante." In Sucede que me canso de ser hombre: Relatos y reflexiones sobre hombres y masculinidades en México. Edited by Ana Amuchastegui and Ivonne Szasz, 241-274. Mexico City: El Colegio de México.

Escobar Latapí, Agustín. 2003. "Men and Their Histories: Restructuring, Gender Inequality, and Life Transitions in Urban Mexico." In Changing Men and Masculinities in Latin America. Edited by Matthew C. Gutmann, 84-114. Durham and London: Duke University Press.

Estes, Carroll L., and Elizabeth A. Binney. 1989. "The Biomedicalization of Aging: Dangers and Dilemmas." The Gerontologist 29 (5): 587-596.

Fishman, Jennifer R., Robert H. Binstock, and Marcie A. Lambrix. 2008. "Anti-aging Science: The Emergence, Maintenance, and Enhancement of a Discipline." Journal of Aging Studies 22 (4): 295303.

Friese, Carrie, Gay Becker, and Robert D. Nachtigall. 2006. "Rethinking the Biological Clock: Eleventhhour Moms, Miracle Moms and Meanings of Age-related Infertility." Social Science \& Medicine 63 (6): 1550-1560. doi: https://doi.org/10.1016/j.socscimed.2006.03.034.

Gammeltoft, Tine M. 2013. "Potentiality and Human Temporality: Haunting Futures in Vietnamese Pregnancy Care." Current Anthropology 54 (S7): S159-S171. doi: 10.1086/670389.

García, Brígida, and Orlandina de Oliveira. 2004. "El ejercicio de la paternidad en el México urbano." In Imágenes de la Familia en el Cambio de Siglo. Edited by Mariz Ariza and Orlandina de Oliveira, 283-320. México, D.F.: Instituto de Investigaciones Sociales, Universidad Nacional Autónoma de México.

García-Deister, Vivette, and Carlos López-Beltrán. 2015. "País de gordos/país de muertos: Obesity, death and nation in biomedical and forensic genetics in Mexico." Social Studies of Science 45 (6): 797-815.

Grace, Victoria, Annie Potts, Nicola Gavey, and Tiina Vares. 2006. "The Discursive Condition of Viagra." Sexualities 9 (3): 295-314.

Gutmann, Matthew C. 1996. The Meanings of Macho: Being a Man in Mexico City. Berkeley: University of California Press.

Gutmann, Matthew C. 2007. Fixing Men: Sex, Birth Control, and AIDS in Mexico. Berkeley: University of California Press.

Hirsch, Jennifer. 2003. A Courtship After Marriage: Sexuality and Love in Mexican Transnational Families. Berkeley: University of California Press.

Huerta Rojas, Fernando. 2007. “El cuerpo masculino como escenario de la vasectomía: una experiencia con un grupo de hombres de las ciudades de México y Puebla." In Sucede que me canso de ser hombre: Relatos y reflexiones sobre hombres y masculinidades en México. Edited by Ana Amuchastegui and Ivonne Szasz, 479-518. Mexico City: El Colegio de México.

Jain, Sarah Lochlann. 2007. “Living in Prognosis: Toward an Elegiac Politics.” Representations 98 (1): 7792, 
Johnson-Hanks, Jennifer. 2002. “On the Limits of Life Stages in Ethnography: Toward a Theory of Vital Conjunctures." American Anthropologist 104 (3): 865-880.

Lamb, Sarah. 2014. "Permanent Personhood or Meaningful Decline? Toward a Critical Anthropology of Successful Aging." Journal of Aging Studies 29: 41-52.

Lamb, Sarah, ed. 2017. Successful Aging as a Contemporary Obsession: Global Perspectives. New Brunswick, NJ: Rutgers University Press.

Loe, Meika. 2004. The Rise of Viagra: How the Little Blue Pill Changed Sex in America. New York: New York University Press.

López-Beltrán, Carlos, and Vivette García Deister. 2013. “Aproximaciones científicas al mestizo mexicano." Hist. ciênc. saúde-Manguinhos 20 (2): 391-410.

Mamo, Laura, and Jennifer Fishman. 2001. "Potency in All the Right Places: Viagra as a Technology of the Gendered Body." Body \& Society 7 (4): 13-35.

Manderson, Lenore, and Carolyn Smith-Morris, eds. 2010. Chronic Conditions, Fluid States: Chronicity and the Anthropology of Illness. New Brunswick, NJ: Rutgers University Press.

Manrique, Linnete. 2016. "Dreaming of a Cosmic race: José Vasconcelos and the Politics of Race in Mexico, 1920s-1930s." Cogent Arts \& Humanities 3 (1): 1218316.

Manrique, Linnete. 2017. "Making the Nation: The Myth of Mestizajes." Anthropol 5 (186). doi: 10.4172/2332-0915.1000186.

Marshall, Barbara L. 2009. "Rejuvenation's Return: Anti-aging and Re-masculinization in Biomedical Discourse on the 'Aging Male.'” Medicine Studies 1 (3): 249-265.

Marshall, Barbara L. 2010. "Science, Medicine and Virility Surveillance: 'Sexy Seniors' in the Pharmaceutical Imagination." Sociology of Health \& Illness 32 (2): 211-224. doi: 10.1111/j.14679566.2009.01211.x.

Marshall, Barbara L., and Stephen Katz. 2002. “Forever Functional: Sexual Fitness and the Ageing Male Body." Body \& Society 8 (4): 43-70.

McLaren, Angus. 2007. Impotence: A Cultural History. Chicago: University of Chicago Press.

Minichiello, Victor, Saifur Rahman, Gail Hawkes, and Marian Pitts. 2012. "STI Epidemiology in the Global Older Population: Emerging Challenges." Perspectives in Public Health 132 (4): 178-181. doi: 10.1177/1757913912445688.

Moreno Figueroa, Mónica G., and Emiko Saldívar. 2015. “'We Are Not Racists, We Are Mexicans': Privilege, Nationalism and Post-Race Ideology in Mexico." Critical Sociology. doi: 10.1177/0896920515591296.

Munn, Nancy D. 1992. “The Cultural Anthropology of Time: A Critical Essay." Annual Review of Anthropology 21:93-123.

Mykytyn, Courtney Everts. 2006. "Anti-aging Medicine: Predictions, Moral Obligations, and Biomedical Intervention." Anthropological Quarterly 79 (1): 5-31.

Nieves Delgado, Abigail. 2020. "The Face of the Mexican: Race, Nation, and Criminal Identification in Mexico." American Anthropologist.

Oudshorn, Nelly. 1994. Beyond the Natural Body: An Archeology of Sex Hormones. London: Routledge. 
Paz, Octavio. [1961] 1985. The Labyrinth of Solitude and other Writings. Translated by Lysander Kemp. New York: Grove Weidenfeld.

Potts, Annie, Victoria Grace, Nicola Gavey, and Tiina Vares. 2004. “'Viagra stories:' Challenging 'Erectile Dysfunction.'” Social Science \& Medicine 59: 489-499.

Ramirez, Josué. 2009. Against Machismo: Young Adult Voices in Mexico City. New York: Berghahn Books.

Riska, Elianne. 2013. “Aging men: Resisting and Endorsing Medicalization.” In Aging Men, Masculinities and Modern Medicine. Edited by Antje Kampf, Barbara L. Marshall, and Alan Petersen, 71-85. London: Routledge.

Sandberg, Linn. 2011. Getting Intimate: A Feminist Analysis of Old Age, Masculinity and Sexuality. Vol. 527: Linköping University Electronic Press.

Shoveller, Jean A., Rod Knight, Joy Johnson, John L. Oliffe, and Shira Goldenberg. 2010. “'Not the swab!' Young Men's Experiences with STI Testing." Sociology of Health \& Illness 32 (1): 57-73.

Smith-Oka, Vania. 2012. “'They Don't Know Anything': How Medical Authority Constructs Perceptions of Reproductive Risk Among Low-income Mothers in Mexico." In Risk, Reproduction, and Narratives of Experience. Edited by Lauren Fordyce and Aminata Maraësa, 103-122. Nashville: Vanderbilt University Press.

Soto Laveaga, Gabriela. 2007. “'Let’s Become Fewer': Soap Operas, Contraception, and Nationalizing the Mexican Family in an Overpopulated World." Sexuality Research \& Social Policy 4 (3): 19-33. doi: 10.1525/srsp.2007.4.3.19.

Stepan, Nancy. 1991. "The Hour of Eugenics": Race, Gender, and Nation in Latin America. Cornell: Cornell University Press.

Stern, Alexandra. 1999. "Responsible Mothers and Normal Children: Eugenics, Nationalism, and Welfare in Post-revolutionary Mexico, 1920-1940." Journal of Historical Sociology 12 (4): 370-397. doi: https://doi.org/10.1111/1467-6443.00097

Tamarkin, Noah. 2018. “Time and Relational Possibility: Cultural Anthropology in 2017.” American Anthropologist 120 (2): 305-327.

Tiefer, Leonore. 1994. "The Medicalization of Impotence: Normalizing Phallocentrism." Gender and Society 8 (3): 363-377.

Tiefer, Leonore. 2006. “The Viagra Phenomenon.” Sexualities 9 (3): 273-294.

van der Geest, Sjaak. 2001. “No strength': Sex and Old Age in a Rural Town in Ghana.” Social Science and Medicine 53:1383-1396.

Vasconcelos, José. 1997. The Cosmic Race: A Bilingual Edition. Translated by Didier T. Jaén. Baltimore: Johns Hopkins University Press. Original edition, 1925.

Vitry, Agnes I, and Barbara Mintzes. 2012. “Disease Mongering and Low Testosterone in Men: The Tale of Two Regulatory Failures." Medical journal of Australia 196 (10): 619-621.

Wardlow, Holly, and Jennifer S. Hirsch. 2006. "Introduction." In Modern Loves: The Anthropology of Romantic Courtship and Companionate Marriage. Edited by Jennifer S. Hirsch and Holly Wardlow, 1-31. Ann Arbor: The University of Michigan Press.

Watkins, Elizabeth Siegel. 2008. “Medicine, Masculinity, and the Disappearance of Male Menopause in the 1950s." Social History of Medicine 21 (2): 329-344. doi: 10.1093/shm/hkn029. 
Wentzell, Emily A. 2008. "Imagining Impotence in America: From Men's Deeds to Men's Minds to Viagra." Michigan Discussions in Anthropology 25: 153-178.

Wentzell, Emily A. 2013. Maturing Masculinities: Aging, Chronic Illness, and Viagra in Mexico. Durham: Duke University Press.

Wentzell, Emily A. 2015. “Medical Research Participation as Citizenship: Modeling Modern Masculinity and Marriage in a Mexican Sexual Health Study." American Anthropologist 117 (4): 652-664. doi: https://doi.org/10.1111/aman.12335

Wentzell, Emily A. 2021. Collective Biologies: Healing Social Ills Through Sexual Health Research in Mexico. Durham: Duke University Press.

Wentzell, Emily A., and Marcia C. Inhorn. 2014. "Reconceiving Masculinity and 'Men as Partners' for ICPD Beyond 2014: Insights from a Mexican HPV study." Global Public Health 9 (6): 691-705. doi: 10.1080/17441692.2014.917690.

Zhang, Everett Yuehong. 2015. The Impotence Epidemic: Men's Medicine and Sexual Desire in Contemporary China. Durham: Duke University Press. 